Supporting Information

\title{
Transient Healability of Metallosupramolecular Polymer Networks Mediated by Kinetic Control of Competing Chemical Reactions
}

Panpan $\mathrm{Li},{ }^{\dagger}$ Yuguo Xia,${ }^{\dagger}$ Jingcheng Hao,${ }^{\ddagger}$ and Xu Wang*,$\dagger$

†National Engineering Research Center for Colloidal Materials, School of Chemistry and

Chemical Engineering, Shandong University, Jinan, Shandong 250100, China

$¥$ Key Laboratory of Colloid and Interface Chemistry and Key Laboratory of Special

Aggregated Materials of the Ministry of Education, Shandong University, Jinan,

Shandong 250100, China

*E-mail: wangxu@sdu.edu.cn 


\section{Supporting Figures}

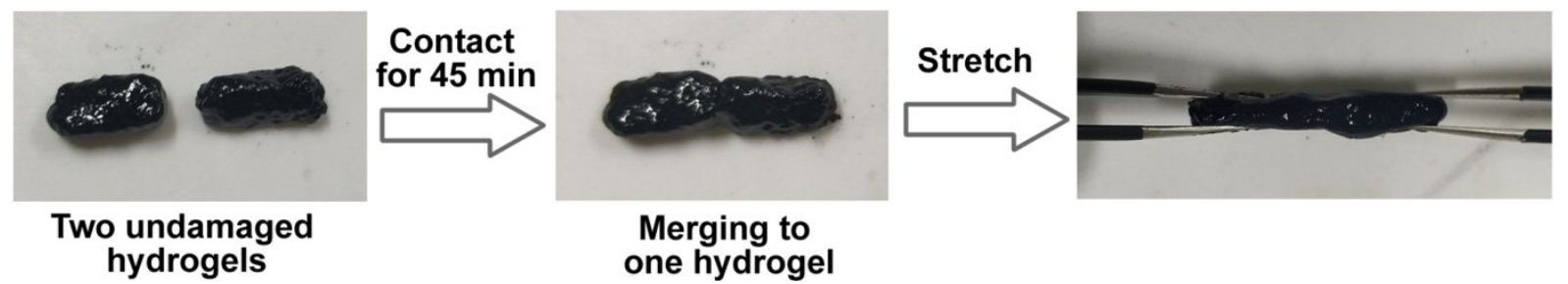

Figure S1. Photographs showing the undesired fusion of two undamaged $\mathrm{Fe}^{3+} / \mathrm{DOPA}-\mathrm{PAH}$ hydrogels based on kinetically labile metal-ligand interactions.

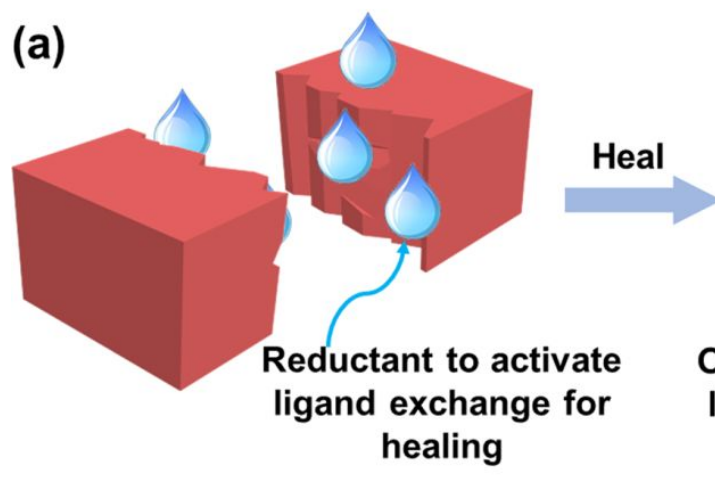

(b) Enzyme

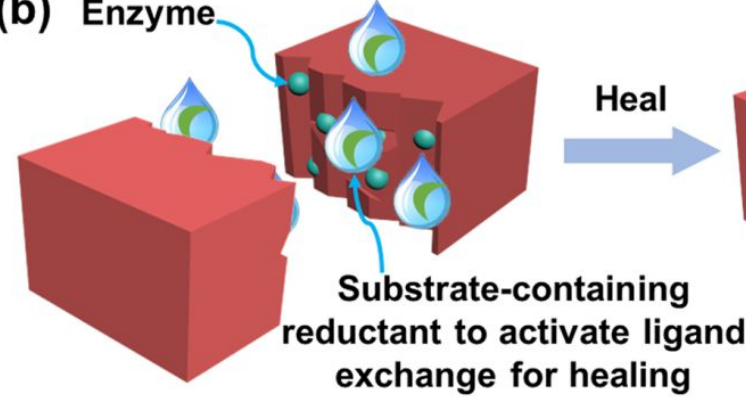

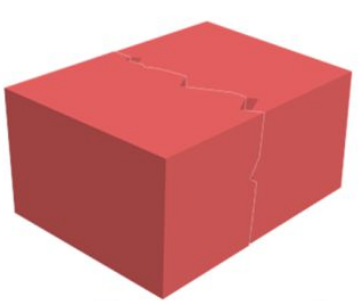

Enzyme-regulated in situ generation of oxidant to deactivate ligand exchange for complete property recovery

Figure S2. (a) When reductants and oxidants are used in sequence to trigger the healing, the second agent have potential difficulty to penetrate deep to the interior of large bulk materials once the damage surfaces contact with each other, resulting in inefficient healing or 
inhomogeneous property recovery. (b) Enzyme-mediated in situ control of the redox property is promising for complete defect healing and material property recovery.

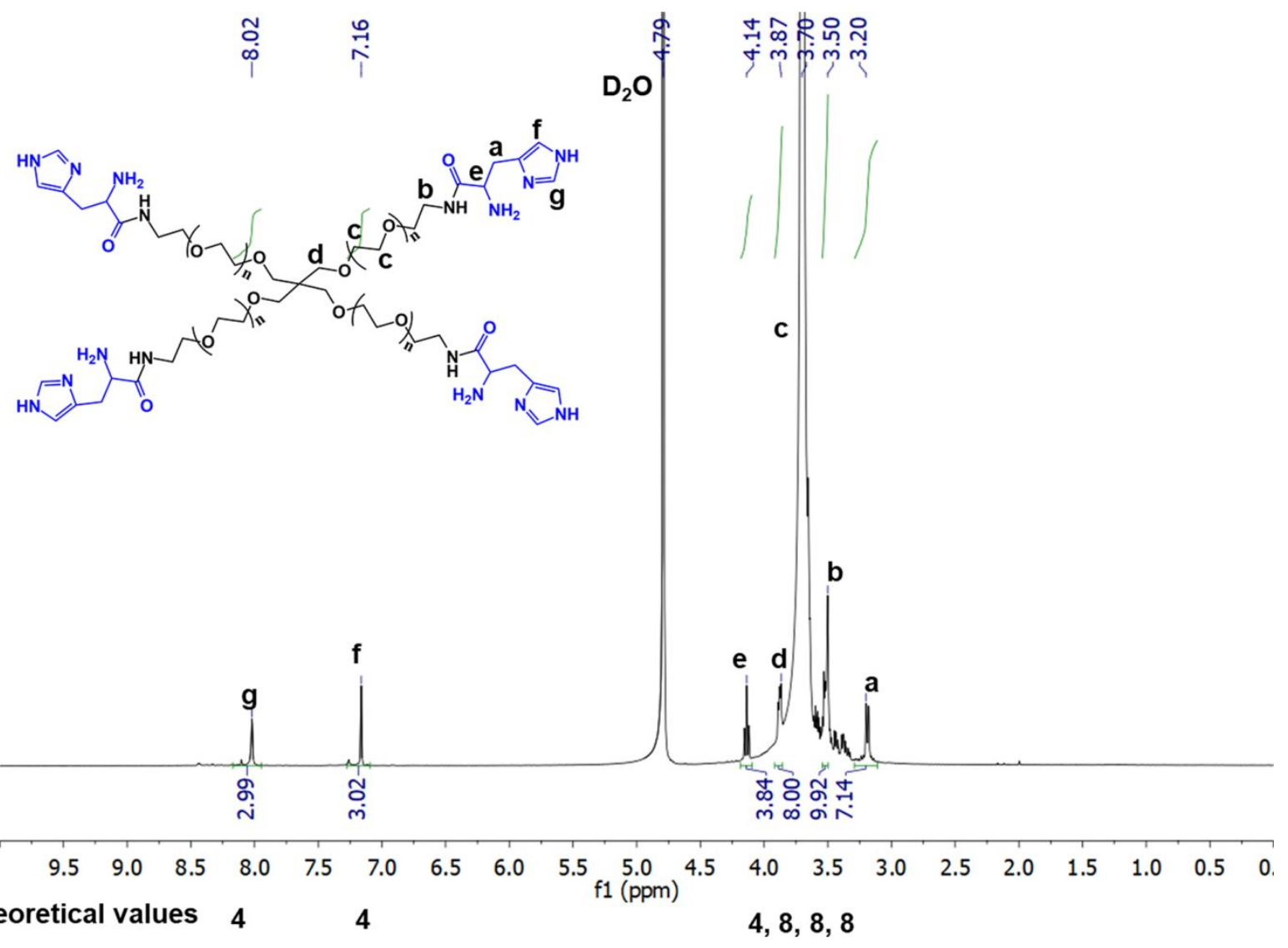

Figure S3. ${ }^{1} \mathrm{H}$ NMR spectrum of $4 \mathrm{~A}-\mathrm{PEG}-\mathrm{His}$ in $\mathrm{D}_{2} \mathrm{O}$. By integrating the characteristic peaks, the grafting ratio of histidine for $4 \mathrm{~A}-\mathrm{PEG}-\mathrm{His}$ is calculated to be $75.8 \pm 12.4 \%$. 

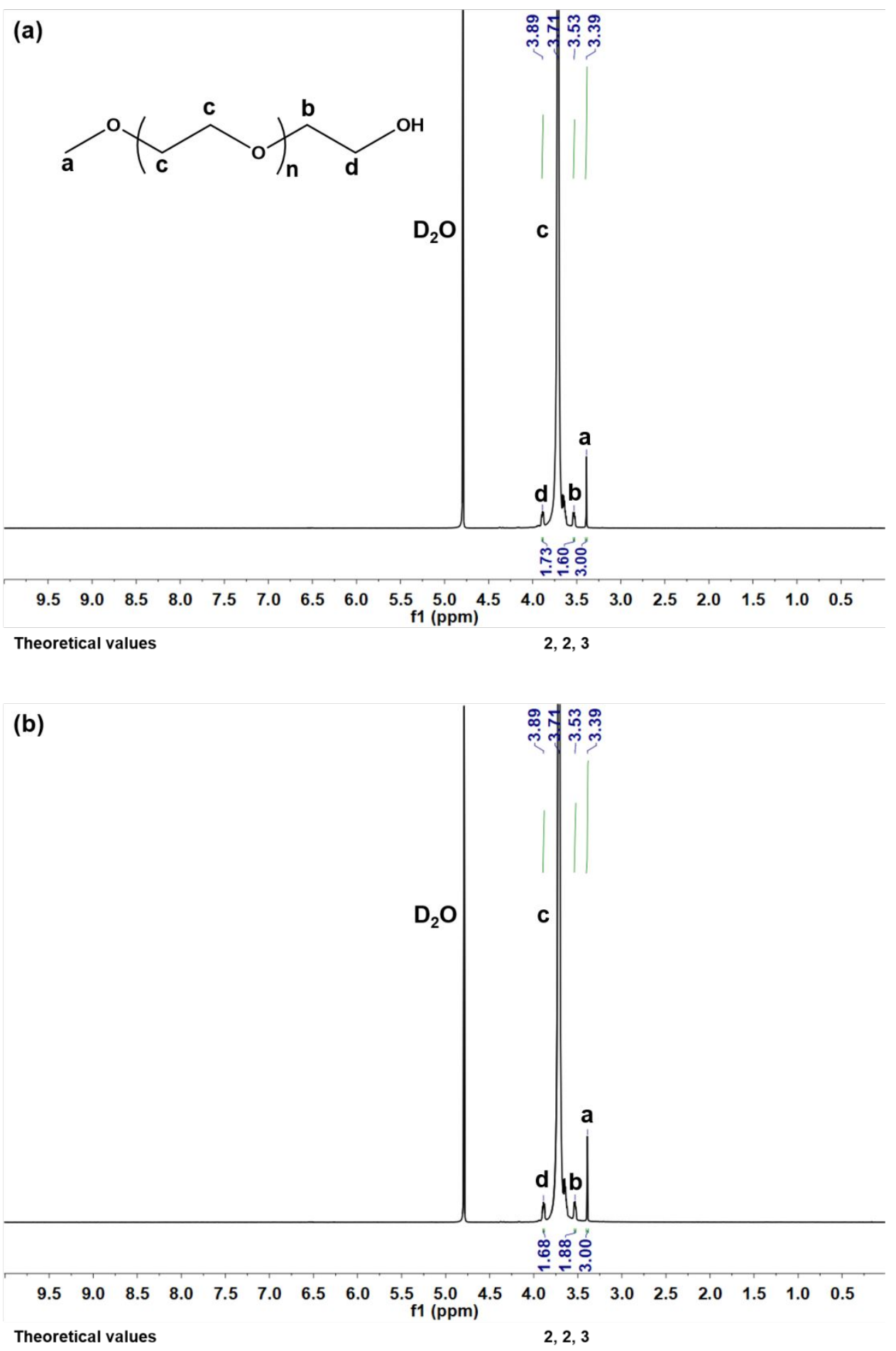

Figure S4. ${ }^{1} \mathrm{H}$ NMR spectra of $\mathrm{mPEG}-\mathrm{OH}\left(M_{\mathrm{w}}=5 \mathrm{kDa}\right)$ before (a) and after (b) the treatment with $\mathrm{H}_{2} \mathrm{O}_{2}$. 


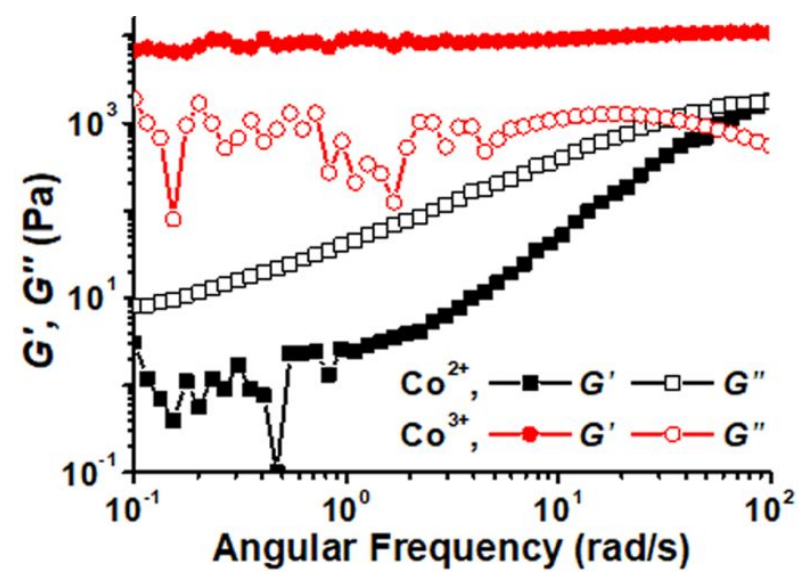

Figure S5. Rheological characterization of the polymer networks without GOX.

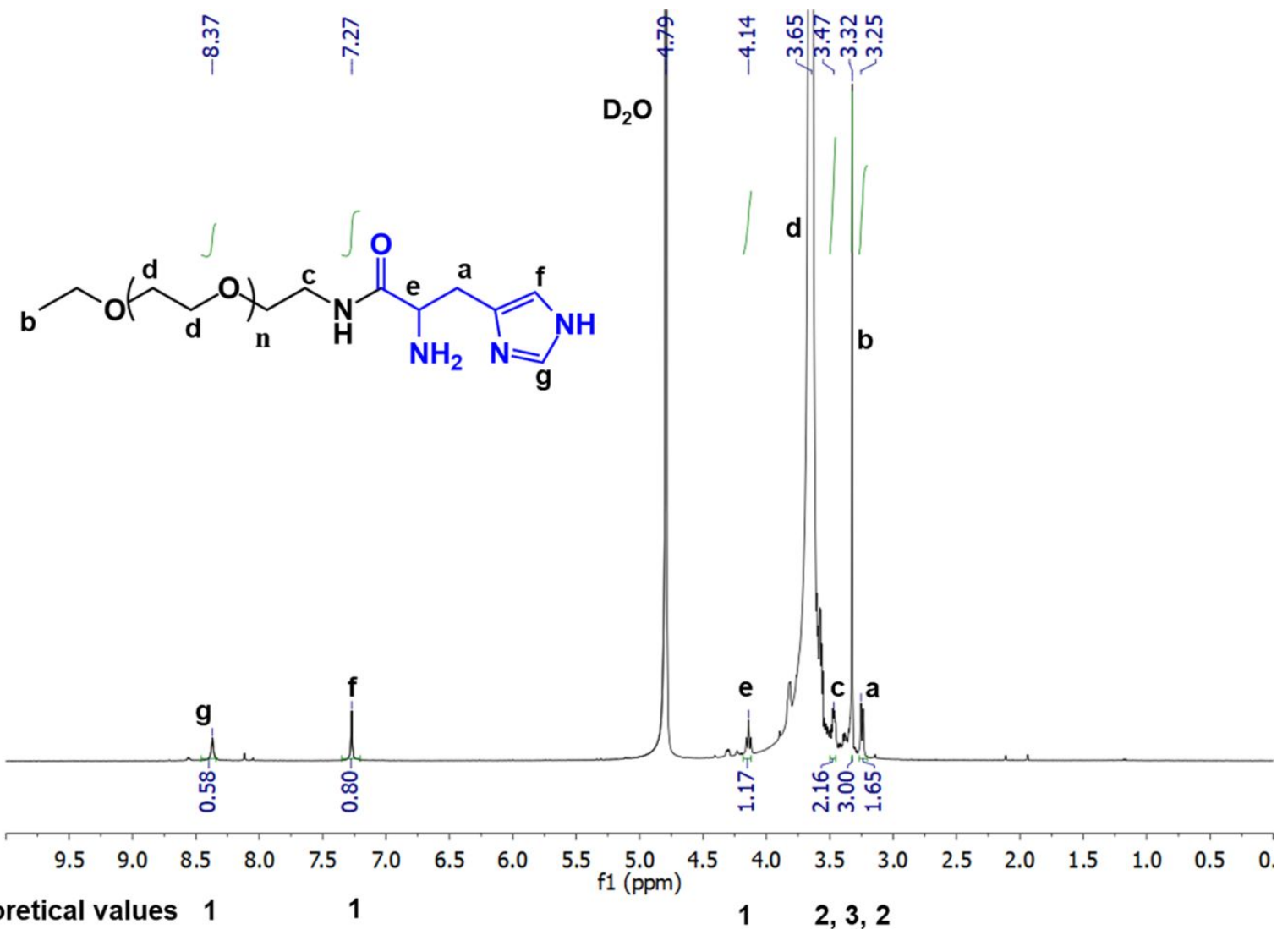


Figure S6. ${ }^{1} \mathrm{H}$ NMR spectrum of $\mathrm{mPEG}-\mathrm{His}$ in $\mathrm{D}_{2} \mathrm{O}$. By integrating the characteristic peaks, the grafting ratio of histidine for $\mathrm{mPEG}-\mathrm{His}$ is calculated to be $81.2 \pm 22.0 \%$.

(a)

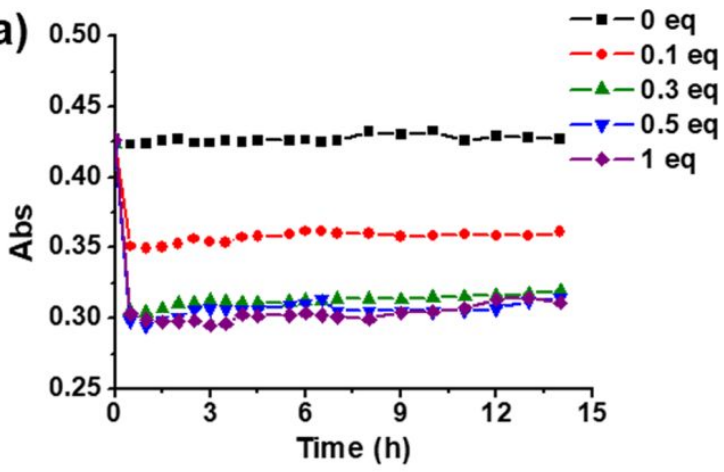

(c)
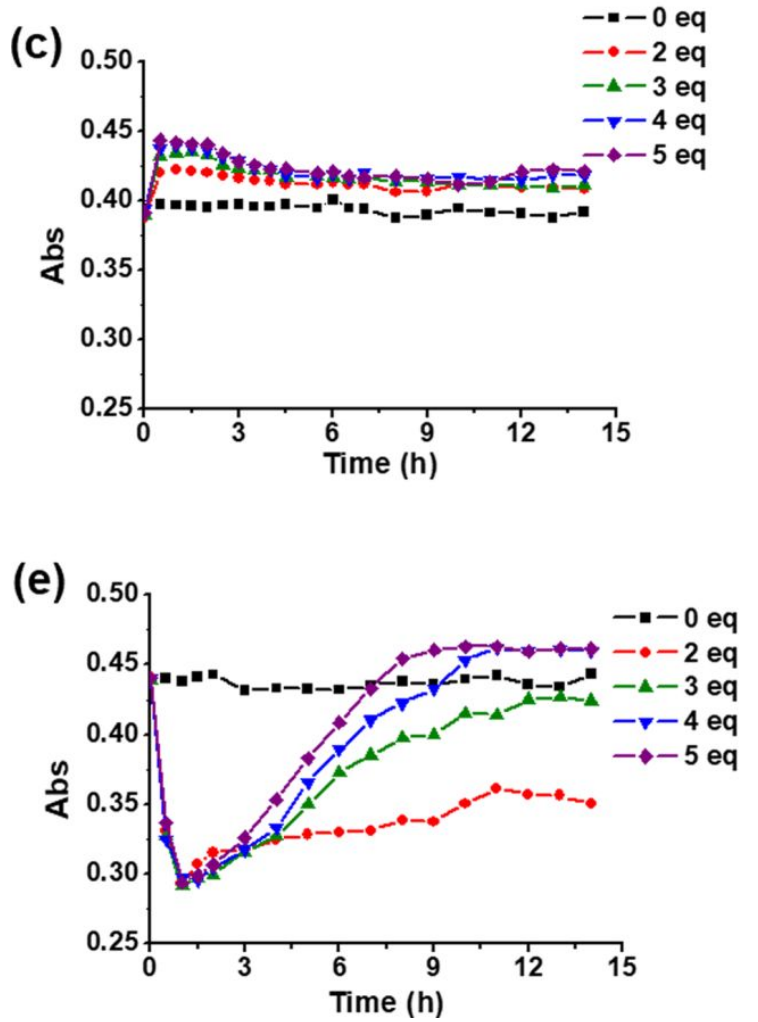

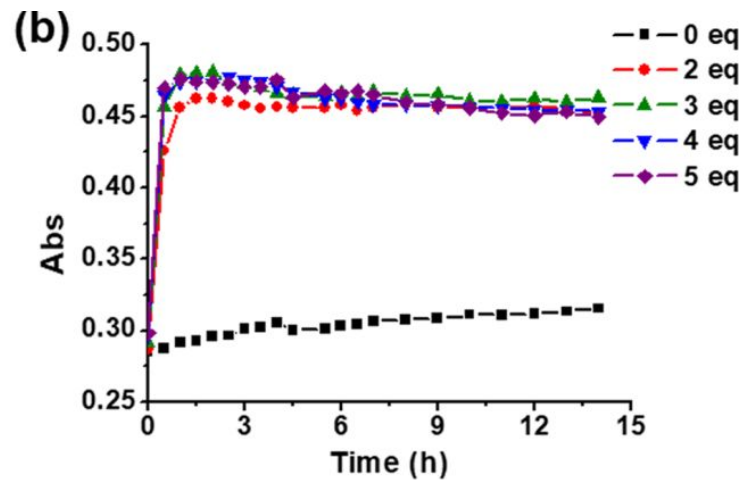

(d)

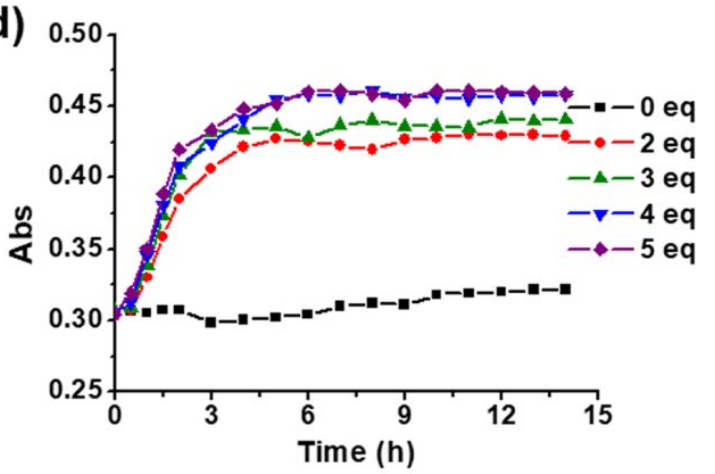

Figure S7. (a, c, e) Time-dependent absorbance at $500 \mathrm{~nm}$ of the solutions containing $40 \mathrm{mM}$ mPEG-His, $13.3 \mathrm{mM} \mathrm{Co}{ }^{3+}$, and $0.4 \mathrm{mg} / \mathrm{mL}$ GOX treated with different equiv (for each equivalent of cobalt ions) of (a) ascorbic acid (AA), (c) $\mathrm{H}_{2} \mathrm{O}_{2}$-containing AA solution, and (e) 
glucose-containing AA solution. (b, d) Time-dependent absorbance at $500 \mathrm{~nm}$ of the solutions in (a) after AA (0.3 equiv) treatment then treated with different equiv of (b) $\mathrm{H}_{2} \mathrm{O}_{2}$ and (d) glucose.

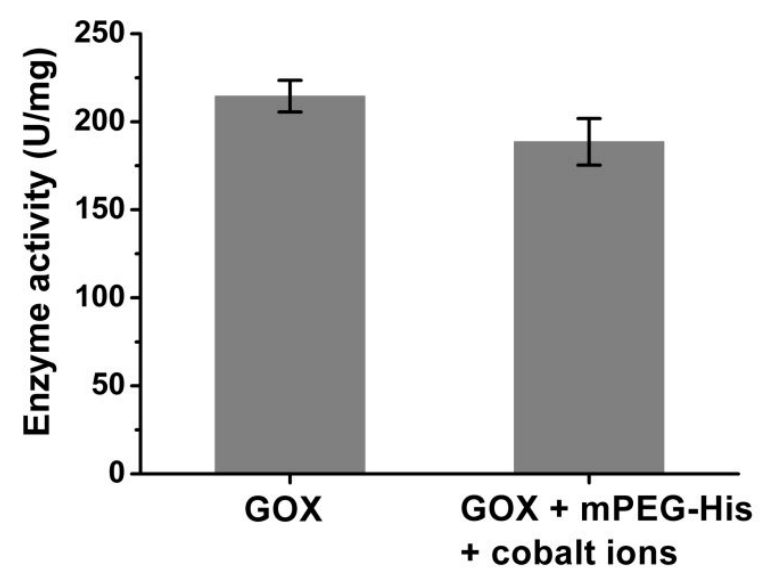

Figure S8. The GOX activities at $25^{\circ} \mathrm{C}$ with and without mPEG-His-coordinated cobalt ions. 

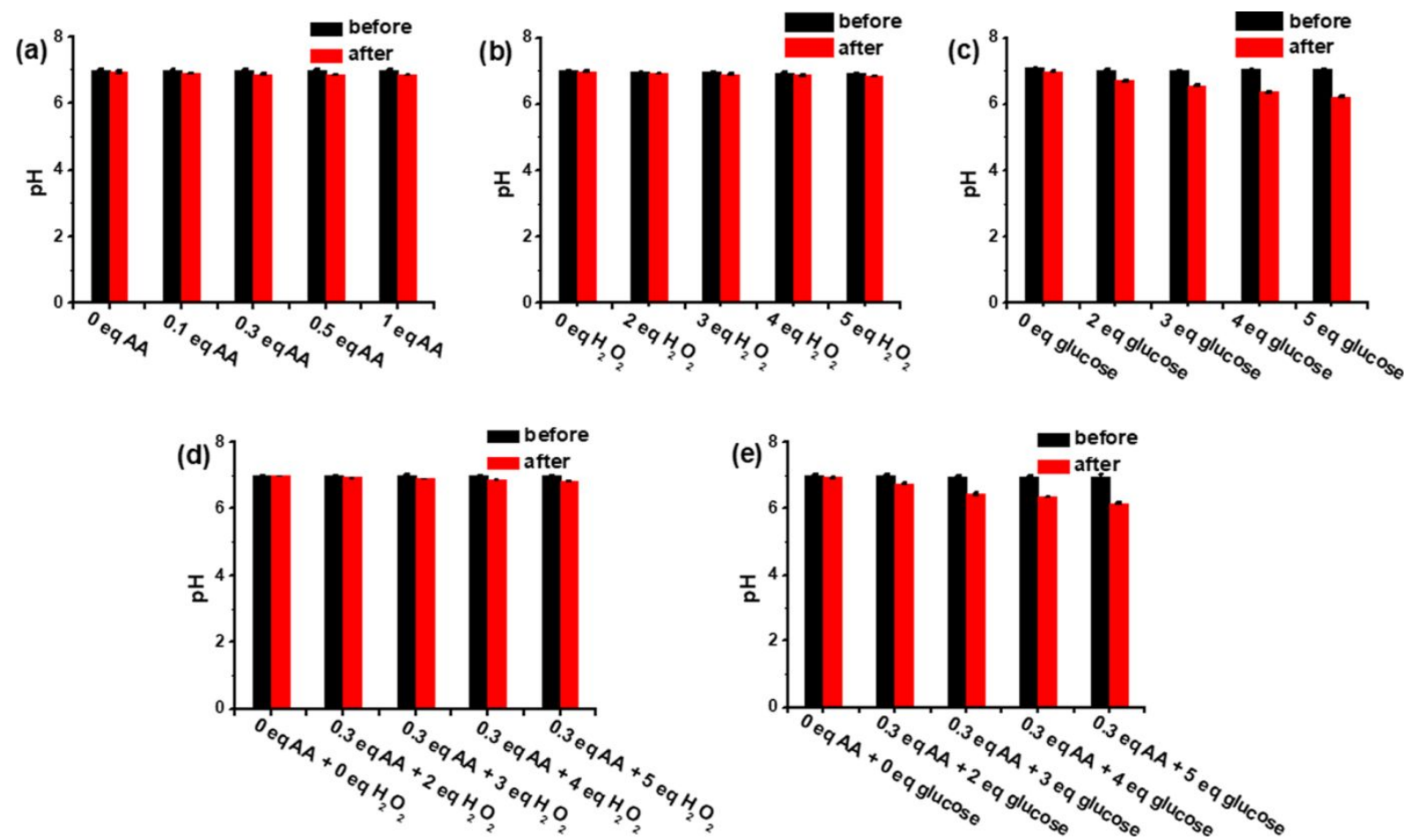

Figure S9. $\mathrm{pH}$ of the solutions containing $\mathrm{GOX}$, cobalt ions $\left[\mathrm{Co}^{2+}\right.$ for (b) and (c), and $\mathrm{Co}^{3+}$ for (a), (d) and (e)], and mPEG-His before and $12 \mathrm{~h}$ after the treatments with (a) ascorbic acid (AA), (b) $\mathrm{H}_{2} \mathrm{O}_{2}$, (c) glucose, (d) $\mathrm{H}_{2} \mathrm{O}_{2}$-containing AA solution, and (e) glucose-containing AA solution. 
(a)

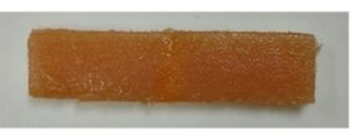

(d)

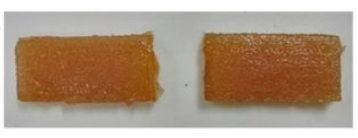

(g)

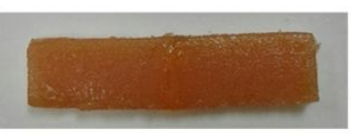

(h)

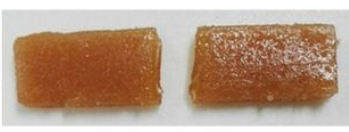

(e)
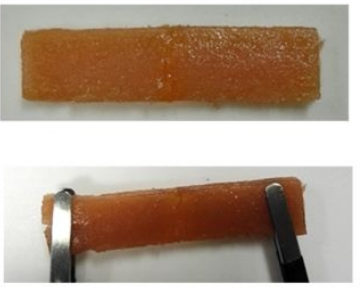

(i)

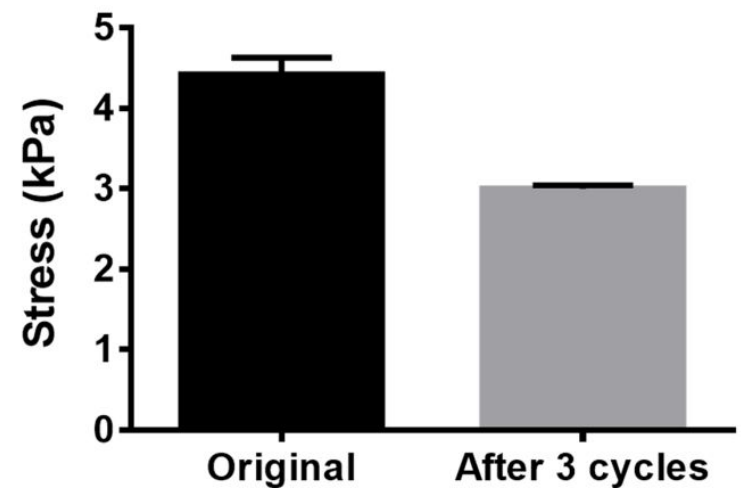

(c)

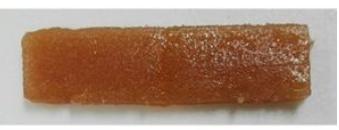

(f)

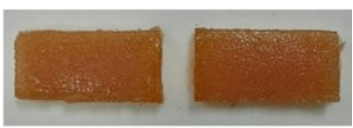

Figure S10. (a-g) The hydrogel with a size of $3.0 \mathrm{~cm} \times 1.0 \mathrm{~cm} \times 0.5 \mathrm{~cm}$ (a) underwent repeated damage (b, d, f) and healing (c, e, g) processes (3 cycles) in the same area. (h) The hydrogel in (g) under stretching. (i) The fracture strength of the hydrogels before and after 3 cycles of repeated damage-healing processes in the same area. The healing efficiency after the 3 cycles of repeated damage-healing processes is calculated to be $72.7 \%$. 


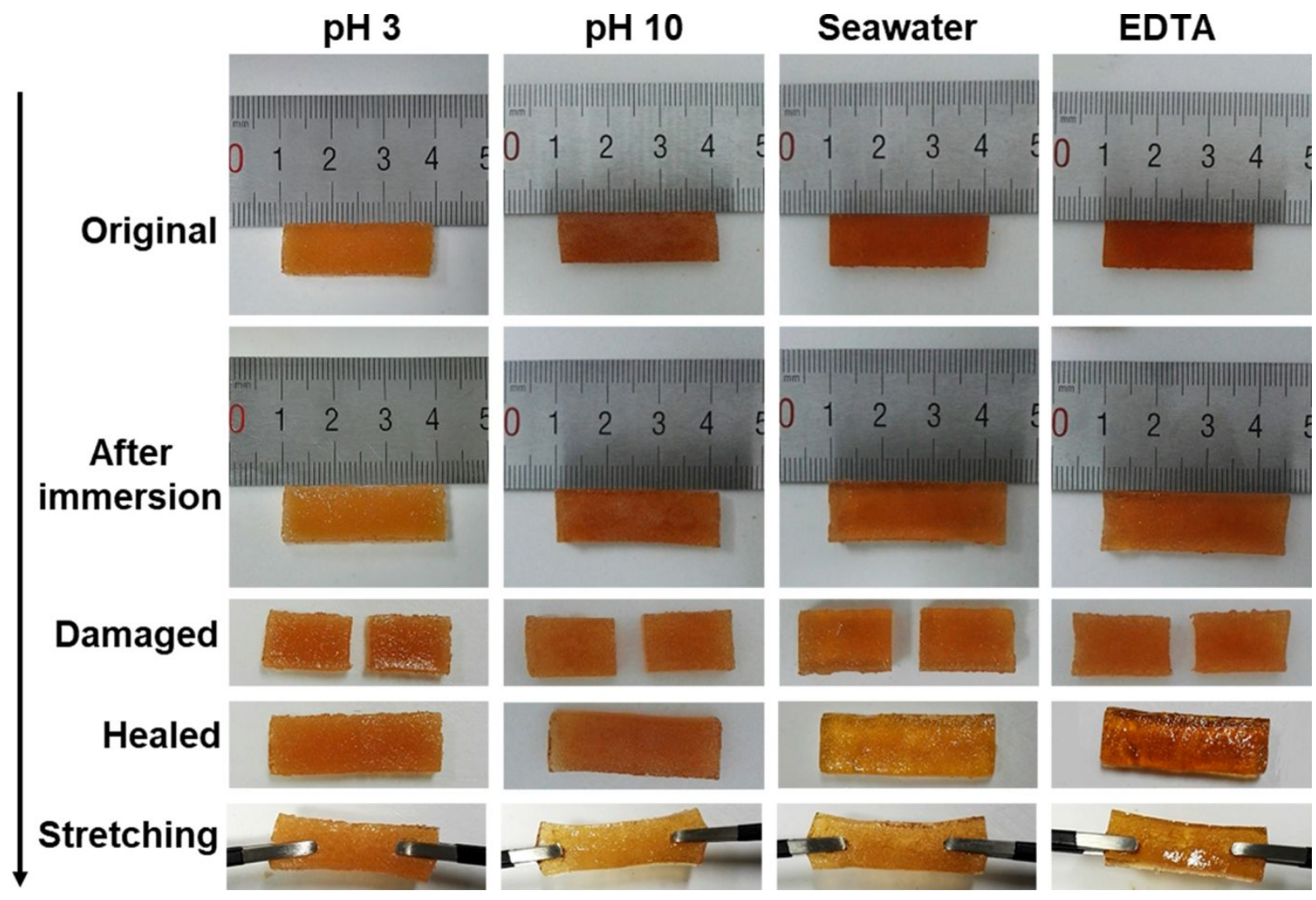

Figure S11. Photographs showing the maintained structural integrity and healing ability of the GOX-containing hydrogels after immersing in acidic media (1 M HEPES pH 3.0), basic media (1 M HEPES pH 10.0), seawater, and EDTA solution $(50 \mathrm{mM})$ for $2 \mathrm{~h}$.

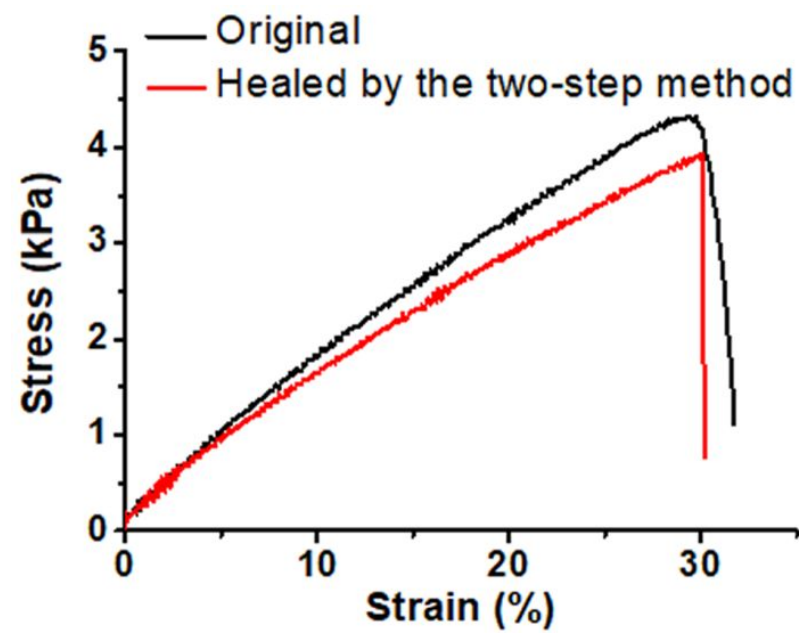


Figure S12. Stress-strain curves of the original and healed GOX-containing hydrogels by treated with ascorbic acid and $\mathrm{H}_{2} \mathrm{O}_{2}$ in sequential order. The healing efficiency for the two-step method is $91.2 \pm 4.4 \%$. 